\title{
Pensando a Sociologia no Ensino Médio Através dos PCNEM E DAS OCNEM
}

\author{
Carolina Dias Cunha Casão ${ }^{1}$ \\ Cristiane Thaís Quinteiro ${ }^{2}$
}

\begin{abstract}
Resumo
Este artigo tem como objetivo uma análise comparativa entre os Parâmetros Curriculares Nacionais - PCN - (1999) e as Orientações Curriculares Nacionais - OCN - (2006) da disciplina de Sociologia no Ensino Médio. Tal análise se pauta em Bernstein (2003), considerando as três dimensões que se influenciam mutuamente: campo da contextualização (intelectuais); campo recontextualizador oficial (Estado, governos, secretarias de educação,); e campo recontextualizador (escola).

Palavras-chave: Ensino de Sociologia. PCN. OCN. Neoliberalismo.
\end{abstract}

\begin{abstract}
This article intend a comparative research between PCN and OCN of Sociology's discipline in the High School. Such analyses rule itself in Bernstein, considering three dimensions that interfluence itself: Contexture field (knowledge productions, brain-works, colleges); re-contexture official field (State, government, education secretaries); and re-contexture field (school, community).

Key words: Sociology Teaching. PCN. OCN. Neoliberalism.
\end{abstract}

\section{INTRODUÇÃO}

$\checkmark$ anto os PCN como as OCN são documentos elaborados no campo da recontextualização oficial (Estado), mas em contextos e por agentes/intelectuais distintos (campo da contextualização). Representam diferentes grupos de poder, projetos políticos, origens nos campos da contextualização, conteúdos, categorias, visões de sociedade, escola, ensino e sociologia. Assim, identificaremos as semelhanças e diferenças

\footnotetext{
${ }^{1}$ Aluna do curso de Especialização em Ensino de Sociologia/UEL e professora do Colégio de Aplicação da UEL.

${ }^{2}$ Professora do Quadro Próprio do Magistério de Sociologia do Estado do Paraná e aluna do curso de Especialização em Ensino de Sociologia - UEL.
} 
entre ambos. Tais discursos produzem práticas pedagógicas e impactos no campo escolar e por isso refletiremos, ao final, sobre nossas próprias práticas pedagógicas enquanto professoras de Sociologia no Ensino Médio. Sendo, portanto, agentes do campo recontextualizador (escola), realizaremos uma auto-reflexão sobre os desafios impostos a uma disciplina de incipiente tradição no currículo nacional.

\section{O Currículo como Produto da Interação ENTRE CAMPOS}

0 currículo não é algo isento de interesses e corresponde a um modelo de sociedade. Conforme Bernstein (2003) demonstra, um currículo éfruto da interação entre o campo da contextualização (academia, universidade, intelectuais, consultores) de onde são recrutados pelo campo recontextualizador oficial (Estado, governos, secretarias de educação) para elaborarem tais documentos. Posteriormente, tais documentos são encaminhados para o campo da recontextualização (escola, comunidade) onde são novamente reelaborados por professores na sua prática pedagógica.

Tanto os PCN - 1999 como as OCN - 2006 de Sociologia no Ensino Médio não têm força de lei, são como o próprio nome diz, parâmetros e orientações. São documentos oficiais elaborados por consultores solicitados pelo Ministério da Educação (MEC), portanto de caráter nacional, mas que podem ser interpretados pelas secretarias estaduais de educação. Ambos documentos estão submetidos às Diretrizes Curriculares Nacionais para o Ensino Médio (DCEM) e a Lei de Diretrizes e Bases da Educação (LDB/1996), estas sim com força de lei. Este dado é significativo no caso da disciplina de Sociologia, pois seu caráter de obrigatoriedade no Ensino Médio só foi conquistado recentemente em 7 de julho de 2006. Assim, para analisar comparativamente os PCN e as OCN, não podemos perder de vista este contexto pela luta da implementação da obrigatoriedade. Ao fazer isso, veremos em que medida tais documentos contribuem ou não para tal luta.

\section{O Conceito de Competência e SuA Recontextualização Pedagógica}

0 conceito de competência tem como seu campo de origem o campo de produção de discursos, nos anos 1960. Da convergência entre estes campos de produção de discurso nas áreas da lingüística, psicologia, antropologia social, sociologia e sociolingüística, teremos, na década de 1990, a recontextualização deste conceito pela pedagogia (BERNSTEIN, 2003), ou seja, a ciência da educação se apropriará do conceito de competência e o adaptará ao seu campo, de diferentes formas, às vezes até opostas, como veremos adiante.

A primeira recontextualização pedagógica do conceito de competência será 
realizada, segundo Kuenzer (2002), pela política escolar de um governo socialista, na França, a fim de acabar com a seletividade no ensino com base na origem de classe. Fazia parte da lógica social do conceito de competência, em sua fase inicial de recontextualização, a idéia de uma democracia universal de aquisição, ou seja, todos os sujeitos possuem uma competência para aprender. Tal pensamento foi apropriado pela perspectiva liberal de ensino, que, ao menos em nível ideológico, garantia o direito da educação para todos, que implicava o mesmo nível de oportunidades e assim, a ascensão social seria possível a todos, dependendo mais do esforço individual das pessoas.

Outro pressuposto da lógica social do conceito de competência afirma que " 0 sujeito é ativo e criativo na construção de um mundo válido de significados e prática" (BERNSTEIN, 2003, p. 78). 0 aluno passa a ser visto como sujeito e não mais como objeto no processo de aprendizagem. Os professores perdem prestígio como socializadores oficiais e em contrapartida as ONGs e a educação informal ganham força no papel da educação. A educação ganha um tom emancipatório e crítico com relação à educação bancária, ou seja, aquela em que o professor é o detentor do saber e que deposita os conteúdos na cabeça dos alunos; "a função dos socializadores não deve ir além da facilitação, acomodação e controle do contexto" (BERNSTEIN, 2003).

Para melhor analisar a pedagogia específica criada pela recontextualização do conceito de competência, Bernstein cria também o modelo pedagógico de desempenho e compara as características destes dois modelos. Com relação à orientação para a avaliação, no modelo de competência enfatiza-se as presenças, isto é, a bagagem já trazida pelo aluno deve ser reforçada, estimulada. Já no modelo de desempenho, avalia-se mais o aluno pelo que faltou, os seus erros. 0 controle é implícito na pedagogia de competência e explícito na pedagogia do desempenho.

0 conceito de competência, tão presente nas pedagogias atuais, é criticado por Kuenzer . Para esta autora, este conceito teve o seu significado alargado, principalmente no campo da educação profissional, para se adaptar às novas exigências do mundo do trabalho, "a fim de conciliar a racionalidade pedagógica e racionalidade econômica" (KUENZER, 2002, p.17). A chamada acumulação flexível que caracteriza o mundo do trabalho contemporâneo requer também trabalhador flexível cujas demandas econômicas exigem indivíduos capazes não apenas de aprender conhecimentos e modos operacionais, mas de "saber, saber fazer, saber ser e saber conviver" (KUENZER, 2002,p.16). Do mesmo modo, o mercado exige um novo tipo de trabalhador, com novos atributos necessários ao trabalho pós-fordista e com capacidades de se adaptar às mais variadas situações de trabalho, já que um emprego estável se torna cada vez mais raro e, destarte, o trabalhador tem que ser flexível para se moldar aos mais diferentes 
trabalhos que realiza durante sua vida, como também ao desemprego estrutural que marca a contemporaneidade.

No Brasil, a introdução do conceito de pedagogia das competências foi feita de cima para baixo, sem um debate prévio nas escolas - campo recontextualizador -, a fim de atender às exigências para concorrer a financiamentos internacionais. Para Kuenzer, o mais grave problema do conceito de competência em sua recontextualização pedagógica é o fato de extrapolar o espaço e tempo escolar (KUENZER, 2002, p.18). Como veremos mais adiante, os PCNEM de 1999 adotam em suas diretrizes este modelo pedagógico de competência, que enfatiza 0 imediato e a resolução de problemas:

traduzir os conhecimentos sobre a pessoa, a sociedade, a economia, as práticas sociais e culturais em condutas de indagação, análise, problematização e protagonismo diante de situações novas, problemas ou questões da vida pessoal, social, política, econômica e cultural. (BRASIL, 1998, p. 19)

Cabe aqui a crítica apontada pela autora, pois estas diretrizes extrapolam as finalidades e capacidades dos alunos do Ensino Médio, o que as tornam vazias, restritas ao campo teórico. Critica o fato de ser uma pedagogia voltada para a legitimação deste mercado e 0 ensino ser voltado para o cálculo econômico. As disciplinas específicas sofrem processo de pasteurização a fim de atender às competências desejáveis do ponto de vista do capital. Na prática esvazia-se a sua atribuição original que é a de ensino; "sobo discurso da valorização da escola como espaço de aprendizagem da crítica e da criatividade, do aprender a ser e a conviver, em substituição ao reles saber, $e$ saber fazer!" (KUENZER, 2002, p.21).

A LDB/96 e as DCNEM - "Conhecimento" e "Estudo" são bem Diferentes de "Disciplina"

A presença da Sociologia no currículo nacional pela LDB-96 se dá de forma ambígua, pois possibilita interpretações diversas as quais serão utilizadas conforme os interesses dominantes de nossa sociedade.

ART 36, $\S 1^{0}$. Os conteúdos, as metodologias e as formas de avaliação serão organizadas de tal forma que ao final do ensino médio o educando demonstre: III domínio dos conhecimentos de Filosofia e Sociologia necessários ao exercício da cidadania.

Este artigo, que parecia anunciar a reinserção destas duas disciplinas ao currículo do Ensino Médio sofreu interpretações durante o governo de Fernando Henrique Cardoso (1995-2002) que impediram a implementação destes conhecimentos na forma de disciplinas específicas obrigatórias dentro da grade curricular. A forma final do artigo foi 
fruto de lutas. 0 ex-deputado Padre Roque do PT enviou um Projeto de Lei ${ }^{3}$, de 1997, que alterava a LDB em seu artigo 36, "dando-lhe uma redação bastante explícita, a saber: fica obrigatória o ensino de Sociologia e Filosofia em todas as escolas de Ensino Médio do país" (CARVALHO, 2004, p.24). Contudo, o projeto para tornar a Sociologia a Filosofia disciplinas obrigatórias do Ensino Médio sofreu uma alta pressão dos lobistas do PSDB e PFL para a sua não implementação a mando do então ministro da educação do governo Fernando Henrique Cardoso, Paulo Renato de Souza. 0 desfecho deste caso durante o governo do PSDB se dá em 8 de outubro de 2001, quando o presidente Fernando Henrique veta o projeto de lei. As DCNEM - Diretrizes Curriculares Nacionais Ensino Médio - Parecer CNE/CEB 15/1998, assim como a Resolução CEN; CEB 03/1998, art. 10 também nos confirmam este desinteresse do Governo Federal em não tornar a Sociologia e a Filosofia como disciplinas obrigatórias.

Nesta área (Ciências Humanas) incluir-se-ão também os estudos de Filosofia e Sociologia necessários ao exercício da cidadania para o cumprimento do que manda a Lei. (BRASIL, 1998).

As propostas pedagógicas das escolas deverão assegurar tratamento interdisciplinar e contextualizado para: b) Conhecimentos de Filosofia e Sociologia necessários ao exercício da cidadania (BRASIL, 1998).

Tanto "estudos" de Sociologia, como "conhecimentos" de Sociologia não asseguram sua oferta enquanto disciplina, afinal, seu "tratamento interdisciplinar" certamente entre as disciplinas já existentes como História e Geografia - dispensaria a necessidade de mais uma disciplina, a Sociologia.

Nota-se, então, que durante os oito anos de governo do PSDB, a políitica educacional brasileira foi orientada pela desregulamentação, com matriz originária do Banco Mundial. Apropria-se do conceito das "competências" dando-lhe uma concepção pragmática de conhecimento de modo que atendesse aos interesses da política neoliberal.

Entre esse novo palavreado veio a tal transversalidade, de forma que seriam criadas então áreas de saber e não matérias, disciplinas. É a desregulamentação chegando ao ensino. Negam-se as disciplinas, como se nega a ciência e o saber dele decorrente. Para eles, ter conhecimento de Sociologia não significa introduzir a disciplina nos currículos dos cursos. Bastaria, digamos, um professor de matemática discutir com seus alunos um artigo de jornal que trate do desemprego em São Paulo, por exemplo, quando entrar na matéria dos percentuais. Ele já

\footnotetext{
${ }^{3}$ Este projeto vinha a atender as reivindicações das entidades estadual e nacional de sociólogos, como da FNSB: Federação Nacional dos Sociólogos - Brasil.
} 
estaria "lecionando Sociologia" aos seus alunos ao tecer comentários sobre a situação do desemprego, concentração de renda, queda de rendimento, etc. "(CARVALHO, 2004, a grifo nosso).

\section{Os PCNEM de 1999: “ConheCimentos DE Sociologia, Antropologia e Política”}

0 parecer do Conselho Nacional de Educação (CNE) sobre as Diretrizes Curriculares Nacionais para o Ensino Médio (DCNEM), aprovado em $1^{\circ}$. de julho de 1998 e as diretrizes estabelecidas no Parecer 15/98 e confirmadas pela Resolução 03/98 trouxeram profundas alterações na estrutura curricular do Ensino Médio, dentre as quais se destacam a instituição de:

I - uma base nacional comum, antigo núcleo comum, organizada não por disciplinas, mas sim por áreas de conhecimento: Linguagens, Códigos e suas Tecnologias, Ciências da Natureza, Matemática e suas Tecnologias e Ciências Humanas e suas Tecnologias. (grifo nosso)

II - um currículo, não mais voltado para a aquisição de conteúdos específicos, mas somente a preparação para o trabalho, habilidades e tecnologias referentes as três áreas de conhecimento (SANTOS, 2004, p.153) (grifo nosso).

Nesta mudança está implícito um projeto pedagógico pautado nos princípios de flexibilidade, interdisciplinaridade e autonomia. A orientação é para as escolas dirigirem seus programas, atividades, projetos e currículos para a preparação básica para o trabalho e para o exercício da cidadania (SARANDY, 2004, p. 118). Tais princípios são norteados pelos quatro pilares da educação, como propõe a Unesco: 0 aprender a conhecer, 0 aprender a fazer, o aprender a conviver e o aprender a ser. Seguindo a mesma lógica, os PCNEM: "Ciências Humanas e suas Tecnologias" afirmam que:

ao desenvolvermos textos específicos voltados para os conhecimentos de História, Geografia, Sociologia e Filosofia, habitualmente formalizados em disciplinas escolares, incluímos diversas alusões - explícitas ou não - a outros conhecimentos das Ciências Humanas que consideramos fundamentais para o Ensino Médio. Trata-se de referências a conhecimentos de Antropologia, Política, Direito, Economia e Psicologia. Tais indicações não visam a propor à escola que explicite denominação e carga horária para esses conteúdos na forma de disciplinas. 0 objetivo foi afirmar que conhecimentos dessas cinco disciplinas são indispensáveis à formação básica do cidadão, seja no que diz respeito a situações concretas do cotidiano social, tais como o pagamento de impostos ou o reconhecimento dos direitos expressos em disposições legais. Na perspectiva do exercício da cidadania, importa em muito o desenvolvimento das competências envolvidas na leitura e decodificação do 'economês' e do 'legalês'”. (BRASIL, 1999). 
Ou seja, há aqui a idéia de competência norteando o ensino e de conteúdos que pertencem a disciplinas específicas, mas que poderiam ser diluídos em outras. Essa prerrogativa abre brecha para se pensar que o mesmo poderia ser feito com a Sociologia, que esta possa ser diluída em História e Geografia, desde que o aluno apreenda as competências de decodificar o jargão da área, o "sociologuês", assim como o "economês" e o "legalês". Além disso, a noção de cidadaniaé atrelada ao imediato, à mera obediência a regras e deveres como pagar impostos e não como superação e aquisição de direitos, mas 0 respeito aos direitos que aparecem de forma naturalizada e como se vivêssemos num Estado de Direito plenamente constituído e consagrado. 0 trecho diz que ficaria a cargo da escola incluir conhecimentos de Sociologia, de acordo com suas disponibilidades, mas a sugestão é de que apareçam em projetos, programas e conteúdos presentes em outras disciplinas, como História, Geografia, etc. Está presente aqui o princípio da autonomia escolar, o que acaba favorecendo a desregulamentação da disciplina de Sociologia. Interessante como se começa o documento logo justificando e sugerindo a dissolução de disciplinas. Afirmar que os conhecimentos de Sociologia e Filosofia foram "habitualmente formalizados em disciplinas escolares" representa uma inverdade histórica, pois sua presença nos currículos sempre foi intermitente, e, além disso, nesta citação estão embutidas intenções que visam sua desregulamentação curricular.

0 trecho dos PCN acima citado reforça uma das interpretações do artigo $36 \mathrm{da}$ LDB de que não seria necessária a implementação da Sociologia e Filosofia como disciplinas específicas e obrigatórias do Ensino Médio apesar de serem consideradas "indispensáveis para a formação básica de cidadão" e para o desenvolvimento das competências envolvidas na leitura e decodificação do 'economês' e do "legalês'. Os próprios termos empregados - "economês" e "legalês" - indicam um tom de ironia e até menosprezo pelos conhecimentos das ciências humanas, como se estas fossem a mera transmissão de jargões. E desta forma, passíveis de serem "desenvolvidas" de maneira transversal nas disciplinas já existentes.

0 último tópico dos PCN é "Competências e habilidades a serem desenvolvidas em Sociologia, Antropologia, Política" ficam evidentes os pressupostos da transdisciplinariedade da pedagogia das competências; sua justificativa não se dá enquanto disciplina, mas enquanto área. No tópico "0 que e como ensinar em Ciências Sociais", dado seu título, supõe-se que os autores informariam quais conteúdos e a maneira de passar esses conteúdos. Porém o que vemosé um apanhado de vários conceitos, na sua maioria apenas citados de maneira genérica sem referência ao escopo teórico de onde provieram, dando a impressão de que o "como" ensinar seria apenas essa coleção conceitual descontextualizada de sua teoria de origem e sem vinculação com a problematização da contemporaneidade, esta sendo caracterizada por intensas transformações no mundo do trabalho (flexibilização das relações do trabalho, 
mundialização) de modo naturalizante e inexorável. 0 "como" ensinar está vinculado ao cotidiano, pois "uma das premissas fundamentais a ser considerada é o partir das experiências culturais dos alunos" (BRASIL, 1999, p.4). Pode-se aqui inferir uma característica da pedagogia das competências queéo aluno ser o sujeito do conhecimento, pois depende da demanda dele e de sua experiência cultural, o melhor (conceito/conteúdo) que serátrabalhado pelo professor. Em várias outras passagens do documento, encontramos o termo "desenvolvimento de competências", que transforma o papel do professor de "transmissor de conteúdos" para o de "facilitador" no processo de desenvolvimento. Dentro deste discurso flexível da pedagogia das competências, podemos perceber também a diminuição de importância atribuída ao professor e mais especificamente ao professor de Sociologia formado em Ciências Sociais.

Qual seria, então, a finalidade do ensino de sociologia, segundo os PCN? Pautandose na LDB/96 que estabelece que a finalidade central do Ensino Médio é a construção da cidadania do educando, a finalidade da sociologia não se encerra em adquirir uma postura mais reflexiva e crítica, mas também, a partir disso o aluno poder intervir na realidade em que vive, pois:

poderá perceber-se como elemento ativo, dotado de força política e capacidade de transformar e, até mesmo, viabilizar, através do exercício pleno da cidadania, mudanças estruturais que apontem para um modelo de sociedade mais justo e solidário (BRASIL, 1999, p.37).

Como se vê, estão presentes objetivos e finalidades que extrapolam a sala de aula, como a transformação da sociedade. Transformação esta que aparece de modo genérico; o que significa "mudanças estruturais que apontem para um modelo mais justo e solidário?" A derrocada do regime capitalista? Provavelmente não, afinal, a problematização da categoria trabalho, segundo os autores, deve ser feita "para além do modelo marxista" (BRASIL, 1999, p. 4). Nisto cai-se no que Kuenzer (2002), denomina como uma das características da pedagogia da competência: com objetivos extra-escolares e irrealizáveis na prática.

\section{As OCNEM de 2006 - "Sociologia”}

A análise das $\mathrm{OCN}{ }^{4}$ de Sociologia nos permitiu compreender que este documento possui uma idéia de políica educacional diferente dos PCN. Numa leitura desatenta, parece que ambos conferem grande importância à Sociologia, mas uma leitura embasada nos permite enxergar que nos $\mathrm{PCN}$, com sua ambigüidade, com o que diz e com o que não diz,

\footnotetext{
${ }^{4}$ Consultores: Prof. Dr. Amaury Cesar Moraes, Profa. Dra. Elisabeth da Fonseca Guimarães, Prof. Dr. Nélson Dácio Tomazi. Leitores Críticos : Pedro Conteratto,Ileizi Luciana Fiorelli Silva, Pedro Tomaz de Oliveira Neto.
} 
não existe a intenção de regulamentar a Sociologia como disciplina obrigatória da grade curricular do Ensino Médio. 0 próprio título das OCN: "Sociologia", se comparado ao título do PCN - "Conhecimentos de Sociologia, Antropologia e Política", nos demonstra esta intenção do documento de 2006 regulamenta a Sociologia em nível nacional.

A começar pelos agentes envolvidos em sua elaboração. Enquanto os agentes responsáveis pela realização dos $\mathrm{PCN}^{5}$, na grande maioria, não têm formação específica em Ciências Sociais, os consultores e leitores críticos das OCN além de serem professores e pesquisadores da área, são comprometidos com esta batalha da obrigatoriedade da Sociologia no Ensino Médio.

Ao contrário dos PCN, as OCN já começam defendendo a especificidade e a identidade da Sociologia com base no panorama histórico da constituição da disciplina nos currículos do Ensino Médio. Mostram-se as intermitências na constituição de uma tradição da disciplina no país, ora entrando, ora ficando fora dos currículos. Assim, o currículo épensado sociologicamente nas suas vinculações com os movimentos de lutas nos diferentes campos que compõem a sociedade. Este viés, eminentemente político, contrasta-se com a visão a-histórica dos PCN que não problematizam a ausência da disciplina no currículo. Desnaturaliza-se, portanto, a idéia de que o currículo é isento de interesses.

As OCN se propõem a ser um mapa, uma proposta de trabalho para orientar 0 trabalho do professor, e não um programa fechado, rígido. Possuem a intenção, e realmente o fazem, de dar força para a consolidação da disciplina de Sociologia.

Esta proposta apresenta-se como mais um passo num processo que, espera-se, seja de consolidação definitiva da presença da disciplina no currículo do ensino médio [...]. Assim, o que se oferece é um ponto de partida, antes de tudo uma avaliação das vantagens e desvantagens de um ou outro recorte programático, e de sugestões metodológicas de ensino, além de breve discussão acerca de recursos didáticos. Tudo isso deve ser entendido como uma tentativa de superar as propostas rígidas e sempre falhas, mas também propostas abertas em excesso, que se mostram inócuas por não conseguirem apresentar sequer uma orientação mínima para os professores (BRASIL, 2006, p.25).

Percebe-se que as OCN tentam recuperar a importância do professor, diminuída

\footnotetext{
${ }^{5}$ A maioria dos agentes que escreveram os PCN não são da área de Sociologia, quando muito são pedagogos, ou de áreas vizinhas, como Geografia (o que demonstra o caráter eminentemente transdisciplinar do mesmo). Um exemplo de como a educação épensada para além dos seus fins educacionais, um dos agentes que escreveu os PCN é Roberto Macedo que é economista, foi consultor do Banco Mundial e do BID, membro do Conselho de Política Econômica da CNI - Confederação Nacional da Indústria (1997-1998). Escreveu livros de títulos como A Formaçãa Educacional para o Novo Mercado de Trabalho e Seu Diploma, sua Prancha - Como Escolher a Profissão e Surfar no Mercado de Trabalho, títulos que combinam muito bem como o tom da defesa naturalizante da flexibilização das relações de trabalho presentes no documento.
} 
pelos PCN. Aprofundam as justificativas para a implementação e vai além do discurso clichêe vazio de "formar o cidadão crítico": "quer-se ultrapassar esse nivel discursivo e avançar para a concretização dessa expectativa" (BRASIL, 2006,p 7). Os autores questionam aidéia de pré-requisito, presentenapedagogia das competências, e, assim, negam aidéia de sequiência entre os conteúdos. 0 "como" ensinar Sociologia aparece de forma interligada aos três recortes metodológicos propostos: conceitos, temase teorias-,sendo que atendênciadaprática costumeira éo professor, os livros e os próprios currículos tratarem separadamente os mesmos. Expõe-se as vantagens e desvantagens de se priorizar um ou outro recorte dentro da sala de aula, além de fornecer exemplos do quê, como e por quê se trabalhar com o que é proposto. Discute-se também a importância de se trabalhar com os autores clássicos, numa linguagem adaptada ao Ensino Médio, assim como a importância de se discutir os temas contemporâneos. Além dos três recortes metodológicos sugeridos, o documento orienta para a pesquisa sociológica no Ensino Médio e faz uma análise crítica de práticas de ensino e recursos didáticos com o fim de reforçar a riqueza e importância da Sociologia e assim propiciar um maior suporte para a regulamentação da disciplina no Ensino Médio. Os recursos sugeridos permitem ao professor utilizá-los para desnaturalizar os fenômenos sociais e causar o estranhamento, como ponto de partidapara as aulas.

Com este mesmo intuito de consolidação da Sociologia como disciplina específica, as OCN empreendem uma forte crítica ao discurso pedagógico das competências que enfatiza a interdisciplinariedade, utilizado pela reforma educacional durante o governo de Fernando Henrique Cardoso (1995-2002).

Como parte do currículo, a Sociologia pode ocupar um papel importante de interlocução com as outras disciplinas ou com o próprio currículo como um todo, senão com a própria instituição escolar. [...]. Por isso, muitas vezes - e particularmente nas DCNEM - se pensa que os "conhecimentos" da Sociologia possam ser tratados pelas outras disciplinas de modo "interdisciplinar"

Reforçando, pois, seu caráter disciplinar e científico, em contraposição ao desenvolvimento de noções defendido pelos PCN:

[...] pensa-se, então, numa disciplina escolar no ensino médio que fosse a tradução de um campo científico específico - as Ciências Sociais. Não se pode entender que entre os 15 e os 18 anos, após oito, nove, 10 anos de escolaridade, o jovem ainda fique sujeito a aprender "noções" ou a exercitar a mente em debates circulares, aleatórios e arbitrários. Parece que nessa fase de sua vida a curiosidade vai ganhando certa necessidade de disciplinamento, o que demanda procedimentos mais rigorosos, que mobilizem razões históricas e argumentos racionalizantes acerca de fenômenos naturais ou culturais (BRASIL, 2006, p.7).

Ainda que ambos documentos, PCN e OCN, tenham sido elaborados sob a vigência 
da LDB/96- de orientação neoliberal, o que vemos são dois documentos distintos quanto a esse propósito. Enquanto os pressupostos dos PCN enfraquecem a obrigatoriedade da disciplina de Sociologia justificada pela transversalidade, e assim, reforçando a interpretação "flexível" dada ao artigo da LDB sobre a reintrodução da Sociologia no Ensino Médio, as OCN, por outro lado, deixam claro a matriz disciplinar da Sociologia.

Se retomarmos o texto de Bernstein neste momento, podemos ver que o modelo pedagógico proposto pelas OCN está mais de acordo com o modelo de desempenho proposto pelo autor. Enquanto os PCN se afinam mais com o modelo das competências, as OCN defendem o ensino-aprendizagem de conteúdos específicos, dentro de disciplinas específicas e obrigatórias, istoé, regulamentadas. É um discurso muito mais "fortemente classificado", que se contrapõe ao discurso flexível e dissolvido da pedagogia das competências.

As OCN também se preocupam em definir melhor os conceitos que nos PCN se apresentavam de forma vaga, abstrata e destarte, vazia, como os conceitos de "cidadania" e "educação para a vida", que nos PCN eram vistos estritamente como direito/dever de votar, ou amplamente como direito/dever de participar da própria organização de sua comunidade e seu pais (BRASIL, 2006, p.8).

As OCN também falam no conceito de cidadania, porém, uma cidadania política, além de definir melhor o sentido de "educação para a vida", pois:

0 ensino médio pode ser entendido como momento final do processo de formação básica, uma passagem crucial na formação do indivíduo - para a escolha de uma profissão, para a progressão nos estudos, para o exercício da cidadania, conforme diz a lei - por isso a presença ou ausência da Sociologia é desde já indício de escolhas, sobretudo no campo político (BRASIL, 2006, p.9).

A implementação das OCN se dá durante o governo Luiz Inácio da Silva (20032006), quando se consegue finalmente a vitória de uma lei que contempla a obrigatoriedade das disciplinas de Sociologia e Filosofia no Ensino Médio, aprovada no dia 7 de julho de 2006. A dificuldade agora para a consolidação destas duas disciplinas na grade curricular, se a lei não for revogada, se localiza dentro das escolas, onde cada instituição possui uma margem de autonomia para definir se terá Sociologia e Filosofia em um ano do Ensino Médio ou nos três anos. "No caso recente, deve-se entender que a ausência da disciplina se prende mais a tensões ou escaramuças pedagógicoadministrativas que propriamente a algum conteúdo ideológico mais explícito" (BRASIL, 2006, p.4).

\section{Impactos no Campo da Recontextualização Pedagógica - Nossa Experiência Pedagógica:}

Como agentes do campo escolar, notamos como éfreqüente nas conversas da sala dos professores o uso de categorias como competências, habilidades, interdisciplinariedade, 
pré-requisitos. Há uma recontextualização do discurso pedagógico oficial, impregnado nas falas dos professores e pedagogos, porém, muitas vezes, reproduzidos sem o real conhecimento dos conceitos e do contexto no qual os mesmos foram produzidos. Esta presença marcante do discurso das competências dentro das escolas é, em grande parte, uma herança do governo de Jaime Lerner (1995-2002), que recontextualizou estapedagogia no Estado do Paraná.

Iniciamos nossa prática pedagógica no ano de 2005 através do concurso público para professor de ensino de Sociologia do Estado do Paraná, quase dois anos antes da aprovação da lei federal que impõe sua obrigatoriedade.

Ainda que o Estado do Paraná tenha se adiantado na inserção da disciplina pela via do concurso público, não regulamentou uma carga horária obrigatória, dando autonomia para as escolas a ofertarem. Isto gera tensões internas no âmbito escolar, tanto quanto à legitimidade da disciplina, quanto às disputas nos momentos de elaboraçã̃o da grade curricular escolar. Deste modo, vivenciamos constantemente em nosso cotidiano escolar a luta pela sua consolidação enquanto disciplina específica.

No caso da Sociologia, uma das dificuldades sentidas até o momento é quanto à seqüência dos conteúdos, já que cada escola possui uma autonomia para inclui-la nas séries que desejar. Um dos desafios épensar num currículo nacional comum ${ }^{6}$ e a definiçã̃o de uma carga horária que seja capaz de contemplar todos os conteúdos. Esse currículo mínimo não aparece de forma categórica nem nos $\mathrm{PCN}$ nem nas $0 \mathrm{CN}^{7}$. Mas pensamos que na defesa da obrigatoriedade, determinada sequiência de conteúdos seja importante para justificar o aumento na carga horária. Nesse sentido, as OCN caem também na flexibilidade. E cair na flexibilidade, sem a defesa de um currículo comum pode ser perigoso em termos políticos, correndo o risco de sua diluição em temas transversais. Além disso, dificulta o trabalho dos iniciantes que não tem parâmetros seguros de quais conteúdos privilegiar.

No Paraná, aSEED 8 avança quanto à determinação de "conteúdos estruturantes" que foram pensados com a ajuda dos professores da rede estadual durante os cursos de capacitação. São eles: "0 Surgimento da Sociologia e Teorias Sociológicas"; "Instituições Sociais"; "Cultura e Indústria Cultural"; "Trabalho, Produção e Classes Sociais"; "Poder, Política e Ideologia"; "Direito, Cidadania e Movimentos Sociais". Outra iniciativa foi a

\footnotetext{
${ }^{6} 0$ professor Leujene Mato Grosso de Carvalho é um dos defensores do currículo nacional comum. Em conferência no Simpósio de Sociologia para professores da rede estadual do Paraná, realizado em outubro de 2006, ele diz que um dos desafios do momento é definir o que e como ensinar. Defende o currículo mínimo nacional porque justamente o projeto neoliberal na educação nega a construção de currículos com base em disciplinas.

70 prof. Nelson Tomazi, durante a palestra "A importância da Sociologia no Ensino Médio"realizada no dia 19/ 10/2006 disse que uma das preocupações dos elaboradores do OCN foi o de não deixá-lo muito rígido quanto aos conteúdos que deveriam ser ministrados.

${ }^{8}$ Secretaria de Estado da Educação do Paraná.
} 
elaboração do livro didático público de Sociologia pelos professores da rede estadual do Paraná, conferindo legitimidade à disciplina.

Jánas experiências de estágio dos graduandos em licenciatura, a nossa impressão e o que temos visto é a maioria dos estudantes optando por um ensino abstrato, academicista, que contempla apenas teorias e conceitos, sem vinculação com temas do cotidiano. Consideramos tal mediação a mais difícil e necessária. Ainda caímos no erro do excessivo "sociologuês", "antropologuês", "politiquês", e o fizemos, sobretudo no primeiro ano, como opção política para demarcar o campo da Sociologia no Ensino Médio como uma matéria de contornos definidos e um repertório conceitual que somente um iniciado na disciplina poderia deter.

Não podemos deixar de mencionar a colaboração de alguns estagiários e do GAES Grupo de Apoio ao Ensino de Sociologia - ambos ligados à UEL, os quais nos auxiliaram com materiais didáticos, sugestões, cursos para professores e os círculos de palestras e oficinas denominados "Semana de Sociologia" que foram realizadas em alguns colégios da rede estadual. Estas ações além de fomentarem 0 interesse dos alunos pela disciplina e complementarem as discussões feitas em sala, contribuiram também para a popularização da mesma no âmbito da escola num contexto de sedimentação da obrigatoriedade da disciplina.

\section{Considerações Finais}

Há um avanço metodológico e político nas OCN, ao simultaneamente defenderem a sociologia como ciência e como disciplina específica ao contrário, os PCN não, eles extrapolam os limites de como tratar a Sociologia, esta passa a ser um instrumento genérico para a construção da cidadania, torna-se um clichê, e como clichê, altamente reproduzido sem reflexão sobre as implicações disso. Esta análise comparativa entre os dois documentos nacionais para o ensino de Sociologia, comprova, aos nossos olhos, a tese de Bourdieu sobre a escola como reprodutora do sistema político-econômico-social (o capitalista, com suas diferentes versões). 0 governo de Fernando Henrique Cardoso (PSDB), um governo alinhado às reformas liberalizantes do estado, teve uma política educacional de acordo. No governo de Luís Inácio Lula da Silva (PT), neoliberal (em menor proporção que o anterior), contudo, com um discurso, ação e uma história mais próximos dos interesses das bases nacionais, a Sociologia e a Filosofia conquistaram vitórias como a regulamentação das mesmas na estrutura do currículo do Ensino Médio de forma obrigatória. Toda esta vitória, que também se expande nas legislações estaduais, é produto de uma forte luta de militantes envolvidos com a Filosofia e Sociologia e da sociedade também, entretanto, esta luta não teria um desfecho favorável se o governo de Lula não a apoiasse. Para compreendermos isto é só retornar ao ano de 2001, quando o Projeto Lei da obrigatoriedade foi vetado pelo presidente Fernando Henrique Cardoso.

Os impactos destes dois documentos no campo de recontextualização pedagógica 
são percebidos, por exemplo, através da força que a disciplina conquista nas escolas: carga horária, estabilidade, recursos humanos e didáticos, etc. Não temos dúvidas de que a Sociologia e a Filosofia são disciplinas importantes, com conteúdos próprios e que por isso merecem a mesma atenção e respeito que as outras disciplinas merecem receber por parte dos governos, dos professores, dos alunos e de toda a sociedade. Enxergamos a obrigatoriedade da Sociologia e Filosofia como um ganho da sociedade brasileira, que nunca vai deixar de precisar compreender sua estrutura social. A luta agora se dirige mais para dentro das instituições escolares, no trabalho dos professores e alunos no ensino aprendizagem das Ciências Sociais. Retrocessos poderão haver, como é comum na história da Sociologia no Ensino Médio, por isso a batalha não pode parar. Pressão política e trabalho contínuo são as únicas maneiras de manter um ensino de ciências sociais de qualidade no Ensino Médio brasileiro.

A análise comparativa entre os PCNe as OCN (2006) nos permite ver o discurso dos PCN (1999) como ideológico, como um instrumento de manutenção da política neoliberal. Ao mesmo tempo em que ele retoma o debate sobre a importância da Sociologia e Filosofia no ensino médio, o que the confere prestígio, ele impede que suas sugestões se concretizem, anuncia-se, implicitamente, como uma teoria sem prática porque não assegura que esta disciplina ganhe espaço e tenha condições de efetuar tudo o que é proposto pelo documento.

\section{REFERENCIAS}

BERNSTEIN, Basil. A pedagogização do Conhecimento: Estudos sobre Recontextualização. Cadernos de Pesquisa, n. 120, p. 75-110, nov. 2003.

BRASIL. Ministério da Educação e do Desporto. Conselho Nacional de Educação. Parecer CNE/CEB n¹5/1998. Diretrizes Curriculares Nacionais Para 0 Ensino Médio. Brasília, 1998.

BRASIL. Ministério da Educação e do Desporto. Conselho Nacional de Educação. Resolução 03/98/CNE. Institui as Diretrizes Curriculares Nacionais para o Ensino Médio. Ciências Humanas e suas Tecnologias. Braślia, 1998.

BRASIL. Ministério da Educação. Orientações Curriculares Nacionais. Brasília, 2006.

BRASIL. Ministério da Educação. Parâmetros Curriculares Nacionais. Brasília, 1999.

CARVALHO, Lejeune Mato Grosso de. A trajetória histórica da luta pela introdução da disciplina de Sociologia no Ensino Médio no Brasil. In: Ijuí: Ed. Unijuí, 2004. p. 24. . Sociologia e ensino em debate.

KUENZER, A. Por que não falamos de competências. Ensino Médio: Construindo uma proposta para os que vivem do trabalho. São Paulo: Cortez, 2002.

SANTOS, Mário Bispo dos. A Sociologia no contexto das reformas do ensino médio. In: . Sociologia e ensino em debate. Ijuí: Ed. Unijuí, 2004. p.153.

SARANDY, Flávio Marcos Silva. Reflexões acerca do sentido da sociologia no ensino médio. In: . Sociologia e ensino em debate. Ijuí: Editora Unijuí, 2004. p. 118.

238 • MEDIAÇões, LoNDRINA, v. 12, N. 1, P. 225-238, JAN/JUN. 2007 